\title{
ANALYSIS OF THE CURATIVE EFFECT OF GaAIAs DIODE LASER THERAPY IN FEMALE INFERTILITY
}

\author{
*Yuki Taniguchi ${ }^{1}$,Toshio Ohshiro ${ }^{2}$,Takafumi Ohshiro ${ }^{1}$ and Katsumi Sasaki ${ }^{1}$ \\ 1: Obshiro Clinic, Shinanomachi, Tokyo, Japan \\ 2: Japan Medical Laser Laboratory, Shinanomachi, Tokyo, Japan
}

\begin{abstract}
Background and Aims: During the lifespan of the female, biochemical changes occur in the ovarian environment. These changes are brought about by numerous endogenous and exogenous factors, and can have a profound effect on ovarian oocyte quality. Oocytes of poor quality may be the cause of female infertility and are a major obstacle in successful assisted reproductive technologies (ART). We have previously reported on the efficacy of low reactive laser therapy (LLLT) using a GaAlAs diode laser device which emits laser light of $830 \mathrm{~nm}$ at an output of $60 \mathrm{~mW}$ to improve the poor quality of oocytes as an adjunctive treatment of refractory female infertility. The aim of this study is to assess the LLLT curative effect.

Subjects and Method: Eight hundred and fourteen female patients who presented at the Ohshiro clinic for treatment of infertility from July 1st, 2000 till December, 2009 were enrolled in the analysis. We analyzed the therapeutic frequency and the therapeutic period (the number of menstrual cycles) between pregnant women and non-pregnant women. Results were expressed as means \pm standard error of mean. The statistical difference was determined with the two-sided Student's t-test and the Mann-Whitney's U test. Differences with $\mathrm{P}<0.05$ were considered significant.

Result: The mean therapeutic frequency and mean therapeutic period in the subjects who gave birth was 3.3 \pm 2.6 times a month and 5.2 \pm 6.1 months, respectively, which correspond to the whole oogenesis period.

Conclusion: We concluded that laser therapy once per week and a period of 5-6 menstrual cycles might be necessary to gain a good curative effect as the laser effect could last 1 week and the competence of oocytes depends on numerous processes taking place during the whole oogenesis period.
\end{abstract}

Key Words: female infertility, ovarian aging, oogenesis, low reactive level laser therapy (LLLT)

\section{Introduction}

In the past 50 years, the tendency to postpone childbearing has spread throughout the developed world. The significant achievements of assisted reproduction technology (ART) created the false impression that childbirth could be safely postponed till late in the usual term of fertility. It has been well-demonstrated that fertility declines dramatically as women age

\section{Addressee for Correspondence:}

Yuki Taniguchi MD,

Ohshiro Clinic

JR Shinanomachi Station Building 2F, 34 Shinanomachi,

Shinjuku, Tokyo 160-0016 JAPAN

Tel: +81-3-3352-0046 Fax: +81-3-3354-1103

E-mail: info@jmll.co.jp beyond their mid-thirties, with only rare pregnancies beyond the age of 45 . Figures released by the Human Fertilization and Embryology authority in 2008 suggest that, over the past 10 years, the average success rate of ART has risen significantly for women younger than 35 , from 25 to 35\%, but has remained less than 10\% for women over 40 (www.hfea.gov.uk). ART merely consists of methods of ensuring fertilization and subsequent transfer of the embryo into the uterus, but has not contributed to the problem of old age and poor responders. Fujii et al have reported the use of low reactive level laser therapy (LLLT) for the treatment of infertility as an adjunct to ART where increased sys-

Manuscript received: October 13th, 2010

Accepted for publication: November 20th, 2010 


\section{ORIGINAL ARTICLES}

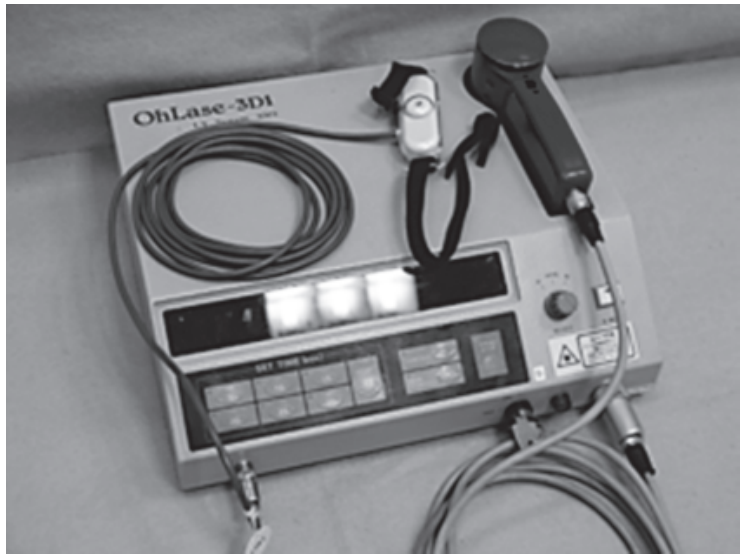

Fig. 1: The Neck Irradiator (Japan Medical Laser Laboratory Corp.)

The small probe attached to the coiled cable is the neck irradiator. The probe is placed somewhere along the posterior portion of the neck. The conventional hand held probe is located in its storage compartment on the right.
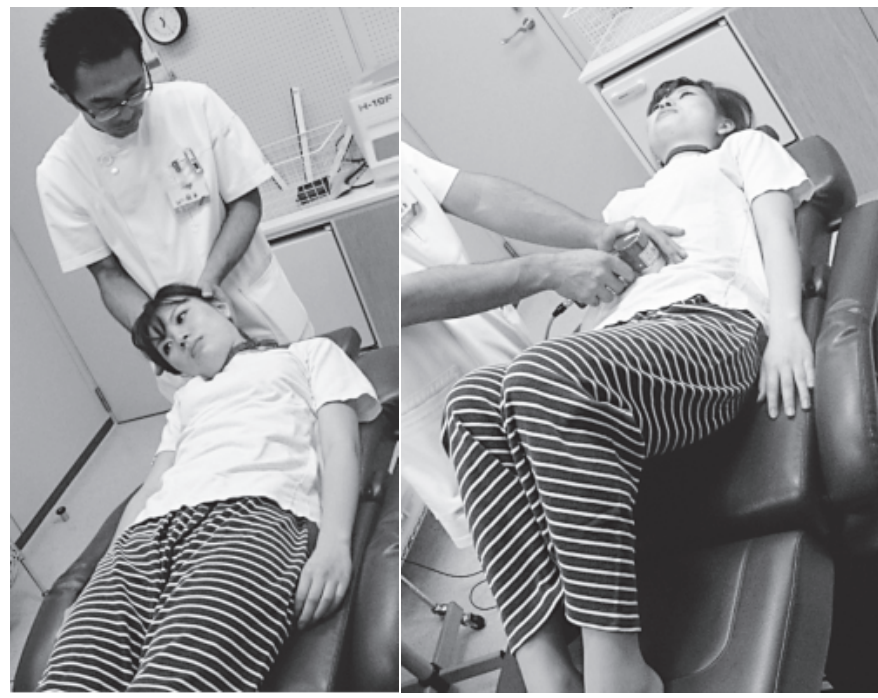

Fig. 2: Treatment scenes: Left: proximal priority treatment, Right: local (abdominal-lumbar area) treatment.

temic blood flow increased the response of the ovary, hence enhanced the response to ART and improved the probability of pregnancy. ${ }^{1)}$ LLLT has improved the successful rate of ART, but the factors which influence the results have as yet remained unclear. The purpose of this report was to elucidate the points which are important to gain good results from LLLT for the treatment of infertility.

\section{Laser hardware}

The Neck Irradiator (Japan Medical Laser Laboratory Corp.) was used for the treatment (Fig. 1). The Neck Irradiator is a two channel GaAlAs diode laser device which emits continuous wave laser light of $830 \mathrm{~nm}$ at an output of $60 \mathrm{~mW}$. Laser light is emitted from either the neck strap probe or from the hand piece, or from both.

\section{Laser procedure}

Patients were placed in a supine position. For the first 10 minutes, proximal priority treatment using the neck strap probe was performed. Proximal priority treatment commences at the proximal region in relation to the two centers of the nervous and circulatory systems followed by treatment of the periphery. The laser is applied solely to the nuchal area while the therapist first stretches the neck region and goes on to stretch

other areas in the order of shoulder, pectoral region, spine, lower back and finally the lower limbs. The second 10 minutes is allotted for local (abdominal-lumbar area) treatment for the stimulation of the reproductive organs (Fig. 2).

\section{Patients and method}

Eight hundred and fourteen patients presented at the Ohshiro clinic for treatment of infertility from July $1^{\text {st }}$, 2000 till December, 2009. Two hundred and twenty-six patients were excluded from this study due to discontinuation of treatment after learning about the treatment or as a result of the clinical examination. The other 588 patients were enrolled in the analysis. In 588 patients, 97 patients became pregnant and 491 patient dids not become pregnant (Table 1). We checked the normal distribution and homogeneity of variance between the age of the pregnant and non-pregnant women. We analyzed the age, the infertility treatment

Table 1. Number of patients

\begin{tabular}{ll}
\hline & All patients: 814 \\
\hline Excluded patients: 266 & Enrolled patients: 588 \\
& Pregnant women: 97 \\
& Non-pregnant women: 491 \\
\hline
\end{tabular}




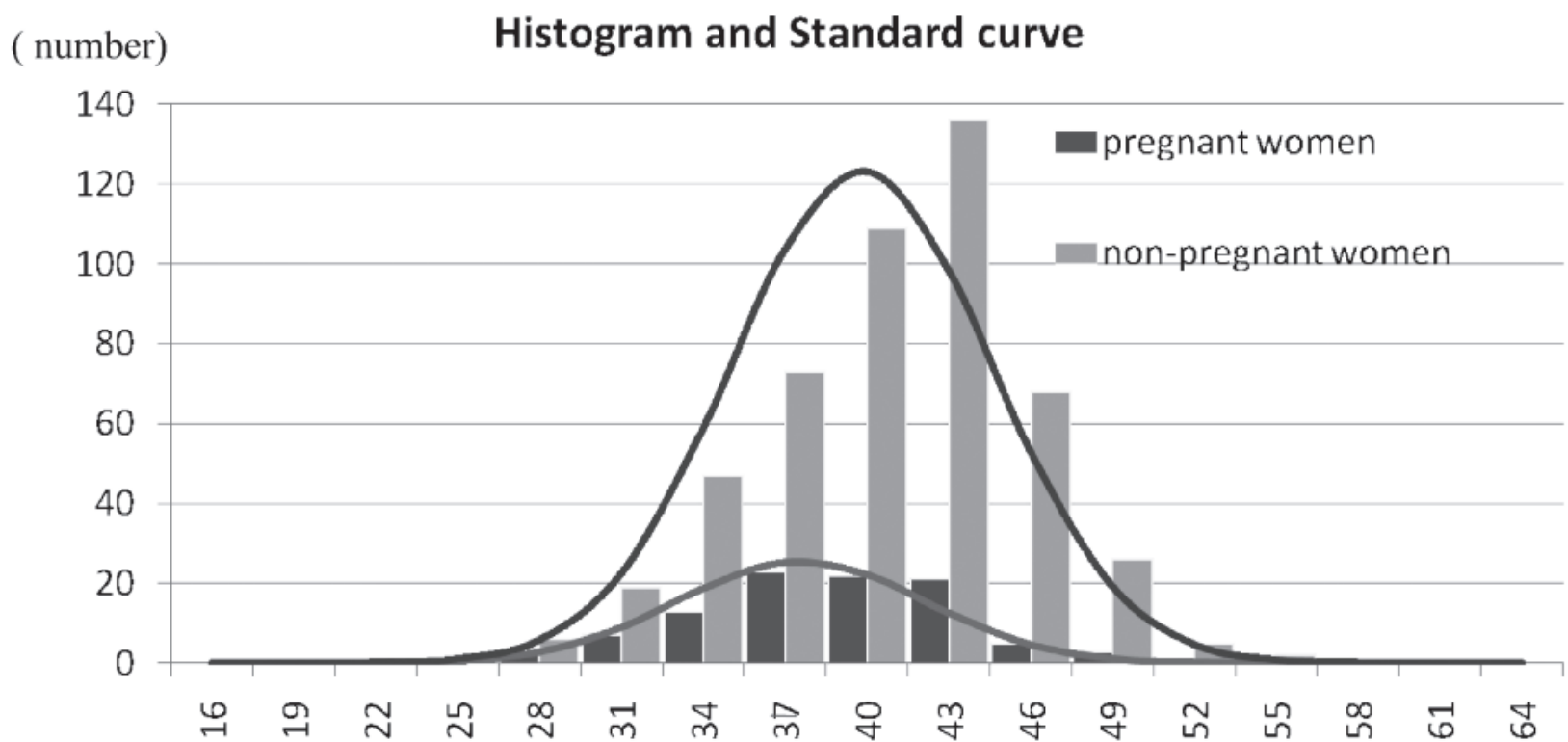

(age )

Fig. 3: The F-test of the age of infertile women.

There was no significant difference in the normal distribution and homogeneity of variance between the ages of pregnant and non-pregnant women.

term, the therapeutic frequency and the therapeutic period (the number of menstrual cycle) between pregnant women and non-pregnant women. Results were expressed as mean \pm standard error of mean. The statistical difference was determined by the two-side Student's $t$-test and the Mann-Whitney U test. Differences with a value of $\mathrm{P}<0.05$ were considered significant. Regarding the therapeutic frequency and the therapeutic period, we compared the data among women who failed to become pregnant (non-pregnant women), women who miscarried (miscarriage women) and women who successfully gave birth (childbirth women).

\section{Result}

There was no significant difference as determined with the two-sided Student's $t$-test in the normal distribution and homogeneity of variance between pregnant and non-pregnant women age (Fig. 3). The mean age of pregnant women was $37.8 \pm 4.5$ years old. The mean age of non-pregnant women was $39.8 \pm 4.8$ years old. The mean infertility treatment term for pregnant women was 3.6 \pm 2.4 years and was $4.4 \pm 3.5$ years for non-pregnant women. The statistical difference was determined by Mann-Whitney's U test. The mean therapeutic frequency in pregnant women was $3.1 \pm 1.4$ times, and was $2.6 \pm 1.3$ times in non pregnant women. The statistical difference was determined by MannWhitney's U test.

The mean therapeutic period in pregnant women was $5.3 \pm 5.5$ periods, and was $4.9 \pm 4.5$ periods in nonpregnant women. There was no significant difference (Table 2). The therapeutic frequency per month increased in turn for non-pregnant women, miscarriage

Table 2. Results of the statistical analyses with the Student's $t$-test and the Mann-Whitney U test

\begin{tabular}{ccccc}
\hline & test & $\begin{array}{c}\text { pregnant } \\
\text { women }\end{array}$ & $\begin{array}{c}\text { non-pregnant } \\
\text { women }\end{array}$ & $\begin{array}{c}\text { statistical } \\
\text { difference }\end{array}$ \\
\hline $\begin{array}{c}\text { Age } \\
\text { (years old) }\end{array}$ & $\begin{array}{c}\text { Student's } \\
\text { t test }\end{array}$ & $37.8 \pm 4.5$ & $39.8 \pm 4.8$ & $\begin{array}{c}\bigcirc \\
(\mathrm{P}<0.05)\end{array}$ \\
$\begin{array}{c}\text { Infertility } \\
\text { treatment term } \\
\text { (years) }\end{array}$ & $\begin{array}{c}\text { Mann- } \\
\text { Whitney's } \\
\text { U test }\end{array}$ & $3.6 \pm 2.4$ & $4.4 \pm 3.5$ & $\bigcirc$ \\
$\begin{array}{c}\text { Therapeutic } \\
\text { frequency } \\
\text { (times) }\end{array}$ & $\begin{array}{c}\text { Mann- } \\
\text { Whitney's } \\
\text { U test }\end{array}$ & $3.1 \pm 1.4$ & $2.6 \pm 1.3$ & $\begin{array}{c}\bigcirc \\
(\mathrm{P}<0.05)\end{array}$ \\
$\begin{array}{c}\text { Therapeutic } \\
\text { period } \\
\text { (periods) }\end{array}$ & $\begin{array}{c}\text { Mann- } \\
\text { Whitney's } \\
\text { U test }\end{array}$ & $5.3 \pm 5.5$ & $4.9 \pm 4.5$ & $\times$ \\
\hline
\end{tabular}


Table 3. Comparison of the three groups (non-pregnant, miscarriage and childbirth women) The therapeutic frequency per month increased in turn with non-pregnant women, miscarriage women and childbirth women. In contrast, the therapeutic period was almost the same among the three groups.

\begin{tabular}{cccc}
\hline $\begin{array}{c}\text { Item } \\
\text { Assessed }\end{array}$ & $\begin{array}{c}\text { Non pregnant } \\
\text { women } \\
\mathrm{n}=491\end{array}$ & $\begin{array}{c}\text { Miscarriage } \\
\text { women } \\
\mathrm{n}=33\end{array}$ & $\begin{array}{c}\text { Childbirth } \\
\text { women } \\
\mathrm{n}=64\end{array}$ \\
\hline $\begin{array}{c}\text { therapeutic } \\
\text { number per } \\
\text { month }\end{array}$ & $\begin{array}{c}2.6 \pm 1.3 \\
\text { (times) }\end{array}$ & $\begin{array}{c}2.9 \pm 1.6 \\
\text { (times) }\end{array}$ & $\begin{array}{c}3.3 \pm 2.6 \\
\text { (times) }\end{array}$ \\
$\begin{array}{c}\text { Therapeutic } \\
\text { period }\end{array}$ & $\begin{array}{c}4.9 \pm 4.5 \\
\text { (periods) }\end{array}$ & $\begin{array}{c}5.4 \pm 4.2 \\
\text { (periods) }\end{array}$ & $\begin{array}{c}5.2 \pm 6.1 \\
\text { (periods) }\end{array}$ \\
\hline
\end{tabular}

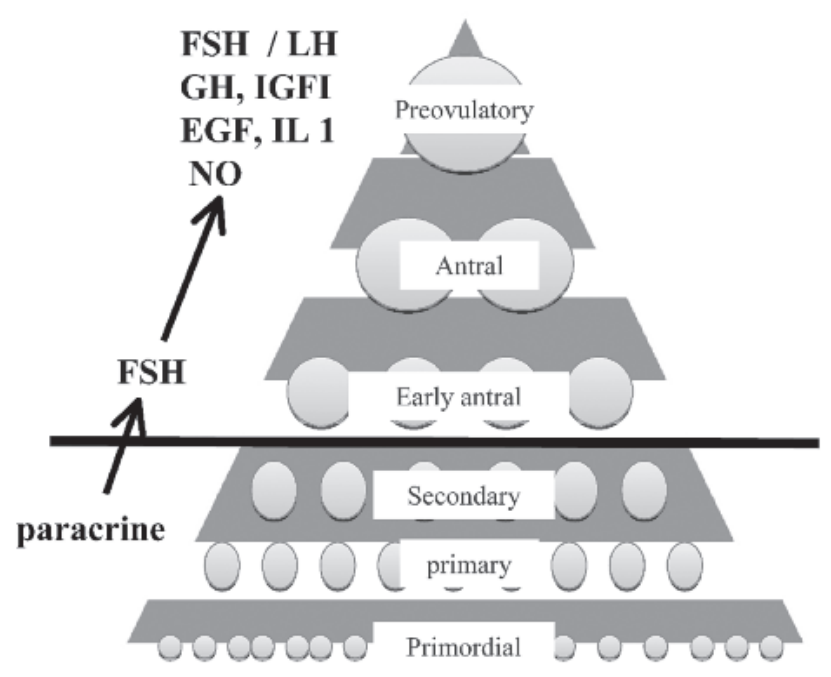

Fig. 4: The follicle mountain: Stage-specific hormonal factors are involved in the survival and development of follicles.

women and childbirth women. In contrast, the therapeutic period was almost the same (Table 3).

\section{Discussion}

The primary cause for female fertility declining with age is the gradual disappearance of oocytes from the oocyte stock that is formed during fetal development. 2) The age-related decline in female fertility is not only due to a declining follicle pool, but is also the result of a decline in oocyte quality. Development of follicles from the smallest primordial and primary follicles to the largest preovulatory follicles requires different stimulatory and survival factors that are stage-dependent (Fig. 4). 3) Systemic blood flow decreases as women grow older. Sore shoulders and coldness of the tips of the extremities are common symptoms seen in older women. Decrease of systemic blood flow and flow to the ovaries might cause the degradation of follicle development and lead to poor oocyte quality because blood-borne trophic and nutritive factors could not reach the developing follicles. Furthermore, meiotic division errors, mitochondrial DNA mutations and aging itself have also been suggested to play a part in the age-associated reduction in oocyte quality. ${ }^{4)}$ Older women seem to have more mitochondrial DNA mutations, which can be responsible for poor implantation and aneuploidy. ${ }^{5)}$ Mitochondrial activation is one of the reported beneficial effects of LLLT. 6) Systemic blood flow increase and the LLLT-mediated mitochondrial activation might contribute to the favorable response to ART and increase the probability of pregnancy.

The LLLT-mediated effect of increased blood flow has been reported as lasting for 3-4 days at least, ${ }^{7)}$ but could not last more than 2 weeks. From this time analysis, successful results could be obtained by more than 3.3 treatment sessions per month. The therapeutic interval was 9.1-9.4 days. This interval might match the period for which the LLLT-mediated effect could last, so we recommend that patients receive LLLT every week, which definitely corresponds to the period for which the LLLT-mediated effect remains latent.

Development of follicles from the smallest primordial and primary follicles to the largest preovulatory follicles takes 5-6 menstrual periods. From this time analysis, we could possibly help to achieve a successful result by treating the patient for more than 5 menstrual periods, which correspond to the whole oogenesis period. The optimal LLLT treatment period to become pregnant might thus be more than 5 menstrual periods.

Finally it has been clear that fertility declines dramatically as women age beyond their mid-thirties. Nikolaou reported the average pregnancy rate following IVF fell from 50\% for women aged less than 35 to $28 \%$ in the $35-38$ age group, $18 \%$ in the $38-39$ group and $12 \%$ in the $40-42$ group. ${ }^{8}$ ) From this time analysis, women who are under 38 years old women have an advantage as far as getting a successful result is concerned. To start LLLT in females below 38 years old and in their early infertility treatment term is important to achieve pregnancy. 


\section{References}

1: Fujii S, Ohshiro T, Ohshiro T, Sasaki K, Taniguchi Y (2007): Proximal priority treatment using the neck irradiator for adjunctive treatment of female infertility. Laser Therapy, 16(3): 133-136

2: Faddy MJ, Gosden RG, Gougeon A, Richardson SJ, Nelson JF (1992): Accelerated disappearance of ovarian follicles in mid-life: implications for forecasting menopause. Hum Reprod, 7:1342-1346

3: Elizabeth A. Mcgee, Aaron J.W. Hsueh (2000): Initial and cyclic recruitment of ovarian follicles. Endocrine Reviews, 21(2):200-214

4: M. Dorland, R.J. van Kooij, E.R. te Velde (1998): General aging and ovarian aging. Maturitas, 30:113118

5: Ana Karina Bartmann, Gustavo Salata Romao, Ester da Silveira Ramos, Rui Alberto Ferriani (2004): Why do older women have poor implantation rate? A possible role of the mitochondria. Journal of Assisted Reproduction and Genetics, 21(3):79-83

6: Smith KC (editor): The science of photobiology ( $2^{\text {nd }}$ edition). 1990, Plenum Publishing Co, New York.

7: Junichiro Kubota, Toshio Ohshiro (1989): The effects of diode laser low reactive-level laser therapy (LLLT) on flap survival in a rat model. Laser Therapy, 1(3):127-133

8: Dimitrios Nikolaou (2008): How old are your eggs. Current Opinion in Obstetrics \& Gynecology, 20:540-544 